\title{
Left Main Coronary Artery Diverticulum: Case Report and Review of the Literature
}

\author{
Hassan Tahir ${ }^{\mathrm{a}}$, Timothy Kennedy ${ }^{\mathrm{a}}$, M. Umer Awan ${ }^{\mathrm{a}}$, Bassam Omar ${ }^{\mathrm{a}, \mathrm{b}}$, \\ Christopher Malozzia ${ }^{\text {, G. Mustafa Awan }}{ }^{\mathrm{a}}$
}

\begin{abstract}
Coronary artery disease is a major cause of morbidity and mortality, and while most commonly is atherosclerotic, it can present with variable manifestations, both congenital and acquired. One such manifestation is coronary aneurysm, which is a localized dilatation of a coronary artery wall segment to greater than 1.5 times the adjacent normal segments. While a dilated outpouching of a coronary artery has been commonly classified as a coronary aneurysm, a non-dilated outpouching is rare and is referred to as a diverticulum, with only one previous case report in the literature. It is conceivable that other cases of coronary artery diverticulum may have been previously reported as an aneurysm, given the overlapping angiographic appearance. We present a case of a 72-year-old female patient with an incidental finding of left main coronary artery diverticulum on diagnostic coronary angiogram done for preoperative liver transplantation evaluation.
\end{abstract}

Keywords: Coronary artery diverticulum; Coronary artery anomalies; Coronary artery aneurysm

\section{Introduction}

Coronary artery disease is heterogeneous and while in most cases is acquired, can also be congenital. Congenital coronary artery anomalies are a diverse group of disorders which are rare and found in less than $1 \%$ of patients on angiography. Coronary artery diverticulum is rare, and was only recently reported in the literature. We present a case of a 72-year-old female patient who was found to have an asymptomatic left main coronary artery diverticulum on diagnostic coronary angiogram.

\section{Case Report}

A 72-year-old Caucasian female with past medical history of

Manuscript submitted March 20, 2018, accepted March 29, 2018

${ }^{a}$ Division of Cardiology, University of South Alabama, Mobile, AL, USA ${ }^{b}$ Corresponding Author: Bassam Omar, Division of Cardiology, University of South Alabama, 2451 USA Medical Dr., Mobile, AL 36617, USA.

Email: omarbassamanwar@gmail.com

doi: https://doi.org/10.14740/cr714w advanced liver cirrhosis, hypothyroidism, atrial fibrillation and mild systolic heart failure was being evaluated for liver transplantation. She had symptoms of shortness of breath on exertion and worsening lower extremity edema. She denied chest pain, palpitations, lightheadedness or syncope. Her electrocardiogram revealed atrial fibrillation with a rate of 58 beats per minute and left bundle branch block. An echocardiogram revealed a left ventricular ejection fraction of $45-50 \%$ with abnormal septal motion, severe tricuspid regurgitation and pulmonary artery systolic pressure of $54 \mathrm{~mm} \mathrm{Hg}$. She underwent elective left heart catheterization for evaluation of her symptoms prior to consideration for liver transplantation. Coronary angiography showed normal coronary arteries, with the exception of a non-aneurysmal outpouching arising from the left main coronary artery which seemed to fill completely with contrast, consistent with a coronary artery diverticulum (Figs. 1 and 2). No collaterals or other fistulous connections were seen arising from the diverticulum. No intervention was deemed necessary and she was treated conservatively for her cardiac risk factors.

\section{Discussion}

Coronary artery disease is a ubiquitous cause of major morbidity and mortality [1]. Commonly this is the result of atherosclerotic disease, which is well characterized with regards to its pathophysiology and treatment [2]. A wide variety of other less common acute and chronic pathologies can also affect the coronary arteries, which may be either acquired or congenital [3]. Such coronary pathologies often resemble equivalent aortic pathologies, yet on a smaller scale, and treatment can be comparable [4].

Obstructive endovascular lesions are most commonly caused by coronary atherosclerosis, which has long been recognized as a multifactorial disease leading to the deposition of lipids in the arterial wall [5], with well-described diagnosis, management [6] and prevention guidelines [7]. Less commonly, fibromuscular dysplasia (FMD) can affect the coronary arteries, predominantly in middle-aged women, but can also occur at any age and in either gender [8]. Coronary FMD has been reported to result in stenosis, aneurysms, dissection, or occlusion of the coronary arteries, and is often treated in a similar manner to coronary atherosclerosis [9].

Coronary vasospasm is a functional abnormality of mildly to moderately diseased segments of the coronary arteries [10]. 

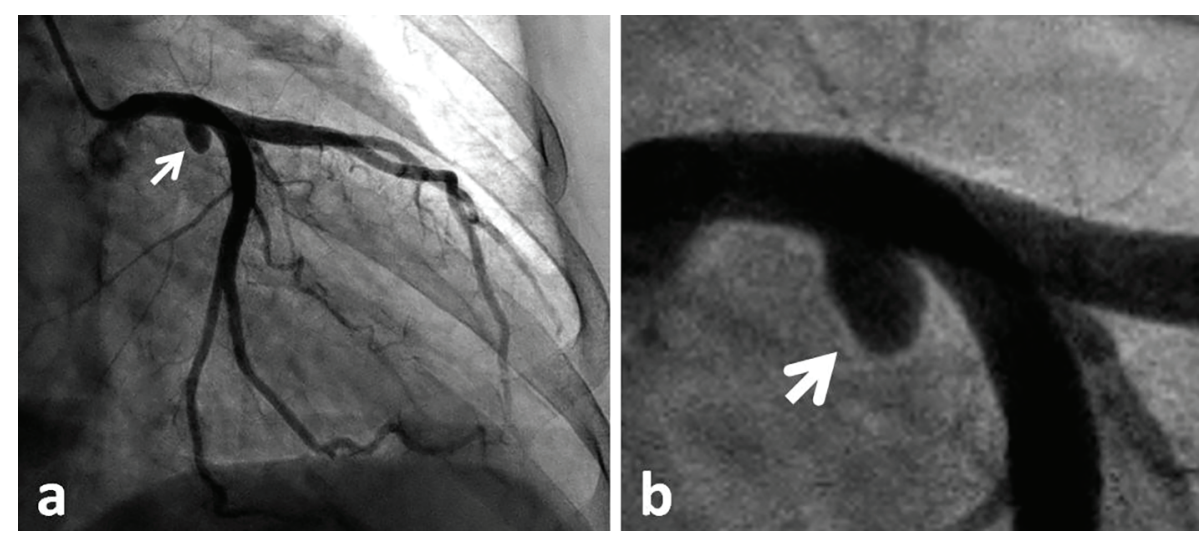

Figure 1. Coronary angiogram: right anterior oblique (RAO) caudal view of the left coronary system (a), with magnification of the left main coronary artery (b), to demonstrate the left main diverticulum (white arrow).

The common pathophysiological phenomenon is vascular smooth muscle hyper-reactivity which causes the spasm [11], with a potential role for vascular inflammation [12]. Management, in general, has focused on removal of offending agents or triggers, in addition to the use of vasodilators including calcium channel blockers and nitrates [13]. Endovascular therapy is usually reserved for recurrent cases despite medical therapy [14] or persistent occlusion causing ongoing myocardial ischemia and infarction [15].

Coronary artery wall abnormalities which mimic aortic syndromes include coronary artery dissection, hematoma and ulcer. Coronary artery dissection is often spontaneous, with several reported predisposing and associated conditions [16]. Iatrogenic, especially catheter-related, coronary dissections have also been reported especially in the setting of coronary artery manipulations during angiography and intervention [17]. Treatment options for coronary dissection have included conservative management [18], endovascular therapy [19] and surgical intervention [20]. Similar to aortic hematomas, coronary artery hematomas have been reported with hemorrhage limited to the media-adventitia layers, resulting in hematoma formation without any identifiable intimal flap [21]. These can be spontaneous [22] or iatrogenic, following coronary stenting [23]. Although ulcerated atherosclerotic coronary lesions are not uncommon, a true coronary artery wall ulcer extending deeply into the intima is rare, with one case reported in the literature and treated conservatively [24]. Treatment of coronary hematomas and ulcers is individualized and is often conservative in the absence of symptoms, thrombosis or embolization.

Coronary artery fistulae have been described draining coronary artery flow into another vascular structure or cardiac cavity [25]. These are mostly congenital [26], with infrequent cases of iatrogenic coronary fistulae reported [27]. Various management options have been proposed based on size and physiology of the fistula, complications and symptoms [28]. Coronary ectasia is diffuse dilatation of the coronary arteries found in $1-6 \%$ of cardiac catheterization procedures, and is often associated with coexisting coronary artery disease [29]. The etiology of coronary ectasia remains unclear; however, histopathologic studies reveal extensive collagen and elastin degradation within the coronary arterial wall [30]. Although ectasia of the coronary arteries can be asymptomatic [31], it has been reported to cause myocardial infarction secondary to embolization [32], coronary artery vasospasm [33, 34] and progression to coronary aneurysm [35]. Ectasia can also affect saphenous vein bypass grafts [36].

Coronary artery aneurysm is a localized dilatation of a
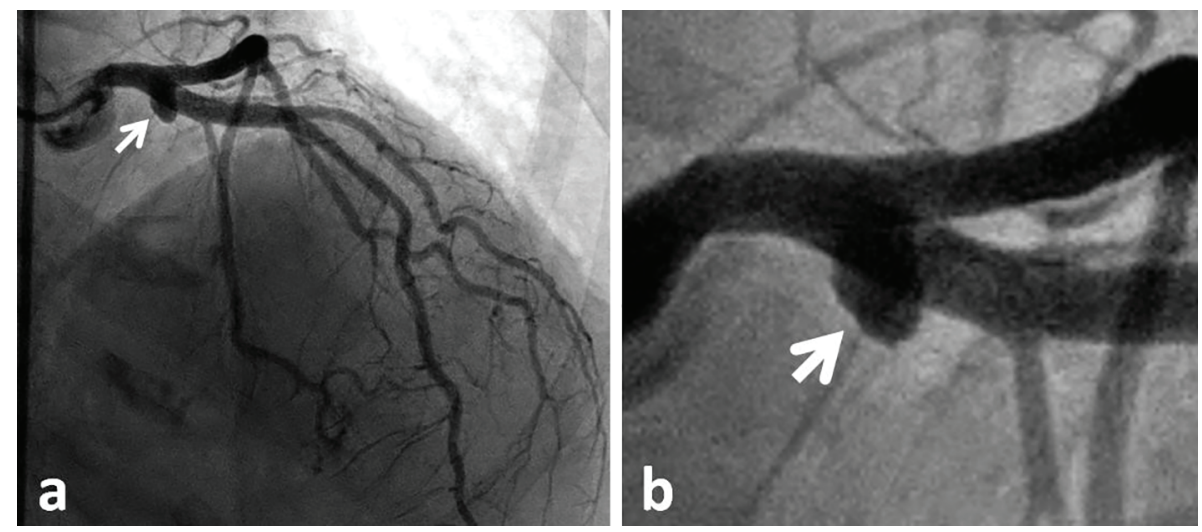

Figure 2. Coronary angiogram: right anterior oblique (RAO) cranial view of the left coronary system (a), with magnification of the left main coronary artery (b), to demonstrate the left main diverticulum (white arrow). 


\begin{tabular}{|c|c|c|c|}
\hline & Pathology & Schematic & Description \\
\hline 1 & $\begin{array}{l}\text { Coronary } \\
\text { atherosclerosis }\end{array}$ & & $\begin{array}{l}\text { Lipid deposition causing plaque formation and } \\
\text { stenosis. Well defined risk factors and treatment } \\
\text { guidelines. Treatment is medical, endovascular } \\
\text { or surgical intervention. }\end{array}$ \\
\hline 2 & $\begin{array}{l}\text { Coronary } \\
\text { fibromuscular } \\
\text { dysplasia }\end{array}$ & & $\begin{array}{l}\text { Segmental, non-inflammatory, non- } \\
\text { atherosclerotic disease of the artery wall } \\
\text { musculature, causing "beaded" appearance. } \\
\text { Treatment is similar to atherosclerosis. }\end{array}$ \\
\hline 3 & Coronary spasm & & $\begin{array}{l}\text { Endothelial hyper-reactivity causing abrupt } \\
\text { interruption of flow and ischemia, rarely } \\
\text { infarction. Treatment is vasodilators. Rarely } \\
\text { requires endovascular intervention. }\end{array}$ \\
\hline 4 & $\begin{array}{l}\text { Coronary } \\
\text { dissection }\end{array}$ & & $\begin{array}{l}\text { Spontaneous or iatrogenic intimal tear causing } \\
\text { intramural hematoma that compresses the true } \\
\text { lumen. Treatment is medical or endovascular } \\
\text { intervention, rarely surgical. }\end{array}$ \\
\hline 5 & $\begin{array}{l}\text { Coronary } \\
\text { hematoma }\end{array}$ & & $\begin{array}{l}\text { Hemorrhage within the media-adventitia layers, } \\
\text { resulting in hematoma formation without any } \\
\text { identifiable intimal flap. Treatment is medical, } \\
\text { occasionally interventional if obstructive. }\end{array}$ \\
\hline 6 & Coronary ulcer & & $\begin{array}{l}\text { Ulceration of an atheromatous plaque that } \\
\text { extends deeply through the intima. Treatment of } \\
\text { underlying atherosclerosis. Endovascular } \\
\text { covered stent if at risk of rupture. }\end{array}$ \\
\hline 7 & Coronary fistula & & $\begin{array}{l}\text { Vascular communication draining coronary } \\
\text { artery flow into another vessel or cardiac cavity. } \\
\text { Treatment is medical; if causes coronary "steal" } \\
\text { and ischemia, endovascular coiling or surgery. }\end{array}$ \\
\hline 8 & Coronary ectasia & & $\begin{array}{l}\text { Diffuse dilatation of the coronary arteries, } \\
\text { usually in atherosclerotic segments. Treatment } \\
\text { of underlying atherosclerosis is medical, with } \\
\text { endovascular intervention in stenotic segments. }\end{array}$ \\
\hline 9 & $\begin{array}{l}\text { Coronary } \\
\text { aneurysms }\end{array}$ & & $\begin{array}{l}\text { Localized dilatation or aneurysmal outpouching } \\
\text { of a coronary segment to }>1.5 \times \text { adjacent } \\
\text { normal segments. Treatment is medical; } \\
\text { interventional with covered stents or surgical if } \\
\text { symptomatic. }\end{array}$ \\
\hline 10 & $\begin{array}{l}\text { Coronary } \\
\text { Diverticulum }\end{array}$ & & $\begin{array}{l}\text { Localized non-aneurysmal outpouching of a } \\
\text { coronary artery segment. Rare and can be treated } \\
\text { similar to coronary aneurysms, medically or } \\
\text { with covered stent, depending on presentation. }\end{array}$ \\
\hline
\end{tabular}

Figure 3. Schematic presentation and brief description of coronary endoluminal lesions.

coronary artery wall segment to greater than 1.5 times the adjacent normal segments, with a reported incidence of up to $5 \%$ of coronary angiograms [37]. Although they are often interchangeably labeled as ectasia, coronary aneurysms tend to be more focal and are associated with several etiologies other than atherosclerosis, including inflammation, infection, trauma and congenital [38]. Inflammatory coronary artery aneurysms are a known complication of Kawazaki disease with well established diagnostic and management guidelines [39]. Coronary aneurysms have also been reported to cause myocardial infarction [40]. Although they are most often isolated, they may be associated with fistulous connections [41]. Infectious coronary aneurysm has also been reported following coronary intervention [42]. Many factors influence management of coronary 
aneurysm, and treatment should be individualized and could include surgical, percutaneous, or medical interventions [43].

A coronary diverticulum refers to a non-aneurysmal (nondilated) outpouching originating from the wall of a coronary artery. To our knowledge, there has been only one previous case report of coronary artery diverticulum in the literature. Shkolnik and Salka [44] reported a 33-year-old female with non ST elevation myocardial infarction who had a right coronary artery diverticulum containing thrombus which was successfully treated with thrombectomy and a covered stent. Our patient was found to have an incidental diverticulum of the left main coronary artery. She suffered advanced liver cirrhosis, which has been associated with various forms of acquired vascular malformations [45]; however, whether her coronary diverticulum is congenital or acquired cannot be discerned.

\section{Conclusion}

Coronary artery diverticulum is a very rare coronary abnormality. It can be asymptomatic and found incidentally on coronary angiography, as in our patient. On the other hand, it may lead to recurrent coronary thrombosis with acute coronary syndrome requiring endovascular intervention. Even though our patient is the second reported case with a coronary diverticulum in the literature, it is conceivable that other cases of coronary artery diverticulum may have been previously reported as an aneurysm or ectasia, given the overlapping angiographic appearance. A classification system of coronary endoluminal disease with well-defined recognition criteria is called for, to avoid misdiagnosis and facilitate proper identification and implementation of necessary therapeutic modalities. Figure 3 provides schematic presentation of various coronary lesions with brief descriptions.

\section{Disclosures}

All authors declare no disclosures related to this manuscript.

\section{References}

1. Sanchis-Gomar F, Perez-Quilis C, Leischik R, Lucia A. Epidemiology of coronary heart disease and acute coronary syndrome. Ann Transl Med. 2016;4(13):256.

2. Bergheanu SC, Bodde MC, Jukema JW. Pathophysiology and treatment of atherosclerosis : Current view and future perspective on lipoprotein modification treatment. Neth Heart J. 2017;25(4):231-242.

3. Hauser M. Congenital anomalies of the coronary arteries. Heart. 2005;91(9):1240-1245.

4. Garg V, Ouzounian M, Peterson MD. Advances in aortic disease management: a year in review. Curr Opin Cardiol. 2016;31(2):127-131.

5. Badimon JJ, Fuster V, Chesebro JH, Badimon L. Coronary atherosclerosis. A multifactorial disease. Circulation. 1993;87(3 Suppl):II3-16.

6. Cassar A, Holmes DR, Jr., Rihal CS, Gersh BJ. Chron- ic coronary artery disease: diagnosis and management. Mayo Clin Proc. 2009;84(12):1130-1146.

7. Stewart J, Manmathan G, Wilkinson P. Primary prevention of cardiovascular disease: A review of contemporary guidance and literature. JRSM Cardiovasc Dis. 2017;6:2048004016687211.

8. Michelis KC, Olin JW, Kadian-Dodov D, d'Escamard V, Kovacic JC. Coronary artery manifestations of fibromuscular dysplasia. J Am Coll Cardiol. 2014;64(10):10331046.

9. Saw J, Bezerra H, Gornik HL, Machan L, Mancini GB. Angiographic and intracoronary manifestations of coronary fibromuscular dysplasia. Circulation. 2016;133(16):1548-1559.

10. Hung MJ, Hu P, Hung MY. Coronary artery spasm: review and update. Int J Med Sci. 2014;11(11):1161-1171.

11. Ong P, Aziz A, Hansen HS, Prescott E, Athanasiadis A, Sechtem U. Structural and functional coronary artery abnormalities in patients with vasospastic angina pectoris. Circ J. 2015;79(7):1431-1438.

12. Hung MJ, Cherng WJ. Coronary vasospastic angina: current understanding and the role of inflammation. Acta Cardiol Sin. 2013;29(1):1-10.

13. McMahon MT, McPherson MA, Talbert RL, Greenberg B, Sheaffer SL. Diagnosis and treatment of Prinzmetal's variant angina. Clin Pharm. 1982;1(1):34-42.

14. Chu G, Zhang G, Zhang Z, Liu S, Wen Q, Sun B. Clinical outcome of coronary stenting in patients with variant angina refractory to medical treatment: a consecutive single-center analysis. Med Princ Pract. 2013;22:583-587.

15. Kultursay H, Can L, Payzin S, Turkoglu C, Altintig A, Akin M, Akilli A. A rare indication for stenting: persistent coronary artery spasm. Heart Vessels. 1996;11(3):165168.

16. Saw J, Mancini GBJ, Humphries KH. Contemporary review on spontaneous coronary artery dissection. J Am Coll Cardiol. 2016;68(3):297-312.

17. Boyle AJ, Chan M, Dib J, Resar J. Catheter-induced coronary artery dissection: risk factors, prevention and management. J Invasive Cardiol. 2006;18(10):500-503.

18. Shah N, Michel J, Aitken SA, Harding SA. Outcomes following conservative management of spontaneous coronary artery dissection. Heart Lung Circ. 2014;23(10):e193-196.

19. Lee SW, Hong MK, Kim YH, Park JH, Rhee KS, Lee CW, $\mathrm{Han} \mathrm{KH}$, et al. Bail-out stenting for left main coronary artery dissection during catheter-based procedure: acute and long-term results. Clin Cardiol. 2004;27(7):393-395.

20. Thistlethwaite PA, Tarazi RY, Giordano FJ, Jamieson SW. Surgical management of spontaneous left main coronary artery dissection. Ann Thorac Surg. 1998;66(1):258-260.

21. Antonsen L, Thayssen P, Jensen LO. Large coronary intramural hematomas: a case series and focused literature review. Cardiovasc Revasc Med. 2015;16(2):116-123.

22. Johnson TW, Smith D, Strange JW, Bucciarelli-Ducci C, Lowe R, Baumbach A. Spontaneous multivessel coronary intramural hematoma: an insight with OCT. JACC Cardiovasc Imaging. 2012;5(10):1070-1071.

23. Tremmel JA, Koizumi T, O'Loughlin A, Yeung AC. Im- 
ages in intervention. Intramural hematoma appearing as a new lesion after coronary stenting. JACC Cardiovasc Interv. 2011;4(1):129-130.

24. Dubois CL, Dens JA. Coronary ulcer. Heart. 2005;91(2):222.

25. Raju MG, Goyal SK, Punnam SR, Shah DO, Smith GF, Abela GS. Coronary artery fistula: a case series with review of the literature. J Cardiol. 2009;53(3):467-472.

26. Tkebuchava T, Von Segesser LK, Vogt PR, Jenni R, Arbenz U, Turina M. Congenital coronary fistulas in children and adults: diagnosis, surgical technique and results. J Cardiovasc Surg (Torino). 1996;37(1):29-34.

27. Banerjee S, Patra S. Coronary-cameral fistula caused by guidewire trauma and resolved by coil embolization. Tex Heart Inst J. 2016;43(4):338-340.

28. Ata Y, Turk T, Bicer M, Yalcin M, Ata F, Yavuz S. Coronary arteriovenous fistulas in the adults: natural history and management strategies. J Cardiothorac Surg. 2009; 4:62.

29. Gunes Y, Boztosun B, Yildiz A, Metin Esen A, Saglam M, Bulut M, Karapinar H, et al. Clinical profile and outcome of coronary artery ectasia. Heart. 2006;92(8):1159-1160.

30. Eitan A, Roguin A. Coronary artery ectasia: new insights into pathophysiology, diagnosis, and treatment. Coron Artery Dis. 2016;27(5):420-428.

31. Carvalho Ede M, Salerno TA, Coy K. Giant coronary artery dilatation in an asymptomatic patient. Rev Bras Cir Cardiovasc. 2009;24(3):413-415.

32. Li Y, Wu C, Liu W. Coronary artery ectasia presenting with thrombus embolization and acute myocardial infarction: A case report. Medicine (Baltimore). 2017;96(4):e5976.

33. Suzuki H, Takeyama Y, Hamazaki Y, Namiki A, Koba $\mathrm{S}$, Matsubara H, Hiroshige J, et al. Coronary spasm in patients with coronary ectasia. Cathet Cardiovasc Diagn. 1994;32(1):1-7.

34. Bove AA, Vlietstra RE. Spasm in ectatic coronary arteries. Mayo Clin Proc. 1985;60(12):822-826.

35. Plehn G, van Bracht M, Zuehlke C, Schrage MO, Wickenbrock I, Perings C, Trappe HJ. From atherosclerotic coronary ectasia to aneurysm: a case report and literature review. Int J Cardiovasc Imaging. 2006;22(3-4):311-316.

36. Sharifi M, Dillon JC, Pompili VJ. Saphenous vein graft ectasia: an unusual late complication of coronary artery bypass surgery. A case report. Angiology. 1999;50(6):497501.

37. Abou Sherif S, Ozden Tok O, Taskoylu O, Goktekin O, Kilic ID. Coronary artery aneurysms: a review of the epidemiology, pathophysiology, diagnosis, and treatment. Front Cardiovasc Med. 2017;4:24.

38. Diaz-Zamudio M, Bacilio-Perez U, Herrera-Zarza MC, Meave-Gonzalez A, Alexanderson-Rosas E, ZambranaBalta GF, Kimura-Hayama ET. Coronary artery aneurysms and ectasia: role of coronary $\mathrm{CT}$ angiography. Radiographics. 2009;29(7):1939-1954.

39. Friedman KG, Gauvreau K, Hamaoka-Okamoto A, Tang A, Berry E, Tremoulet AH, Mahavadi VS, et al. Coronary artery aneurysms in kawasaki disease: risk factors for progressive disease and adverse cardiac events in the US population. J Am Heart Assoc. 2016;5(9):e003289.

40. Pasha AK, Jokerst CE, Janardhanan R. Myocardial infarction related to a coronary artery aneurysm. Am J Med. 2015;128(2):e5-6.

41. Cao H, Ye L, Chan P, Fan H, Liu Z. Giant coronary artery aneurysm with fistula to the pulmonary artery complicated by frequent ventricular premature contractions: a case report. Medicine (Baltimore). 2015;94(7):e530.

42. Kobayashi N, Shibata Y, Hata N, Shimizu W. Formation of infectious coronary artery aneurysms after percutaneous coronary intervention in a patient with acute myocardial infarction due to septic embolism. JACC Cardiovasc Interv. 2017;10(3):e21-e22.

43. Cohen P, O'Gara PT. Coronary artery aneurysms: a review of the natural history, pathophysiology, and management. Cardiol Rev. 2008;16(6):301-304.

44. Shkolnik I, Salka S. Proximal right coronary artery diverticulum resulting in recurrent distal embolization. J Invasive Cardiol. 2011;23(11):E249-250.

45. Alcolado R, Bowry J, Winwood PJ, Loehry CA. Systemic arteriovenous malformations: a feature of advanced liver disease. Gut. 1994;35(8):1145-1147. 